Original Article

\title{
GINGER LOADED CHITOSAN NANOPARTICLES FOR THE MANAGEMENT OF 3-NITROPROPIONIC ACID-INDUCED HUNTINGTON'S DISEASE-LIKE SYMPTOMS IN MALE WISTAR RATS
}

\author{
R. M. AKILA*, DONA MARIA SHAJI \\ Department of Pharmaceutics, College of Pharmacy, Sri Ramakrishna Institute of Paramedical Sciences Coimbatore, Tamilnadu, India \\ Email: akilakathiresan1973@gmail.com \\ Received: 16 Aug 2021, Revised and Accepted: 12 Nov 2021
}

\begin{abstract}
Objective: The purpose of this research work is to enhance bioavailability and brain delivery of ginger through the development of ginger-loaded chitosan nanoparticles and evaluation of its neuroprotective potential against 3-Nitropropionic acid (3-NP) induced Huntington's Disease model rats.

Methods: Ginger-loaded chitosan nanoparticles were developed as five different formulations (F1-F5) by the ionic gelation method. Based on their release, formulations F1 and F3 were chosen for physicochemical characterization. The neuroprotective activity of formulations F1 and F3 were evaluated by behavioural (Neurological scoring, Hanging wire test, Elevated plus maze test), biochemical (estimation of lipid peroxidation, glutathione, protein, superoxide dismutase, catalase) and neurochemical (estimation of acetylcholine esterase inhibition) tests in comparison with ginger extract in Huntington's Disease (HD) model rats.

Results: Formulations F1 and F3 showed almost similar and significant controlled release. Formulation F1 showed spherical nanoparticles with optimum size range and negative zeta potential. The behavioural assessment revealed that there was an improvement in gait, movement, grip strength and memory in ginger-loaded chitosan nanoformulations administered to rats than ginger extract administered rats. Biochemical and neurochemical analyses also proved that ginger-loaded chitosan nanoformulations had greatly lowered the oxidative stress parameters such as malondialdehyde and protein carbonyls in comparison with ginger extract $(\mathrm{p}<0.05)$. The ginger nanoformulations had highly increased the activity of antioxidant enzymes such as superoxide dismutase, glutathione and catalase by reducing the formation of free radicals than ginger extract $(\mathrm{p}<0.05)$. The memory and cognition of ginger nanoformulations administered Wistar rats had highly improved than ginger extract administered Wistar rats $(\mathrm{p}<0.05$ due to inhibition of acetylcholine esterase enzyme).
\end{abstract}

Conclusion: The current study indicated that ginger-loaded chitosan nanoparticles have a superior neuroprotective effect than their extract due to their nano size, which facilitates their entry across the blood-brain barrier and eventually improves the bioavailability of ginger.

Keywords: Huntington's disease, Ginger loaded chitosan nanoparticles, Ionic gelation, 3-Nitro propionic acid

(C) 2022 The Authors. Published by Innovare Academic Sciences Pvt Ltd. This is an open access article under the CC BY license (https://creativecommons.org/licenses/by/4.0/) DOI: https://dx.doi.org/10.22159/ijpps.2022v14i1.42894. Journal homepage: https://innovareacademics.in/journals/index.php/ijpps.

\section{INTRODUCTION}

Huntington's disease (HD) is a rare, genetic, neurodegenerative and ultimately fatal disease. At present only progression delaying treatment is available. HD is caused by a trinucleotide cytosineadenine-guanine (CAG) repeat expansion in the Huntington gene. Typically HD patients present with a triad of cognitive, behavioural and motor symptoms [1]. It has a prevalence of 5 to 10 persons per 100,000 worldwide, which makes it the most common inherited neurodegenerative disorder. Reports say that the prevalence rate of HD in India could be similar to that of the European population, which translates to about 40,000 to 70,000 ill individuals. The mechanisms that account for this selective neuronal death are multifaceted and several lines of evidence suggest that mitochondrial dysfunction, overproduction of reactive oxygen species (ROS) and oxidative stress (an imbalance between pro-oxidant and antioxidant systems resulting in oxidative damage to proteins, lipids and deoxyribonucleic acid) might play important roles.

Ginger (Zingiber officinale) is one of the most widely used dietary condiments in the world. India is its largest producer has produced it as a tonic root for over 5000 y to treat many ailments as an antioxidant, anti-inflammatory agent, anti-nausea compound and anticancer agent. The mechanism of neuroprotective action of ginger is not fully known, but it may be attributed to the antioxidant effect of active bio-ingredient 6-shogaols could inhibit the microglia cells during the occurrence of transient ischemia [2]. The neuroprotective effect of ginger was studied against 3-NP induced Huntington's disease rat model [3]. 3-Nitro propionic acid intoxication is used as a model of Huntington's disease in primates, rats and more recently in mice [4] because it is a mitochondrial neurotoxin that mimics many of the characteristic features of HD such as energy impairment, excitotoxicity and oxidative stress [5].

Treatment of neurodegenerative diseases with nanoparticles may have significant outcomes such as biocompatibility, biodegradability, improvement of therapeutic efficacy and reduction of adverse drug effects [6] and the biodegradable chitosan polymer makes it possible with its unique nature. Some of the reported research on chitosan as a nano vehicle indicate that chitosan-based formulations are suitable systems for targeted drug delivery to the brain $[7,8]$. So, the current research work focuses on the development of ginger loaded chitosan nanoparticles and studies its neuroprotective effect against the rat model of 3-nitropropionic acid-induced Huntington's disease.

\section{MATERIALS AND METHODS}

\section{Chemicals}

Chitosan (85\% deacetylated), sodium tripolyphosphate were obtained from Sigma Aldrich, Mumbai, India and tween 80 was purchased from S. D Fine-Chem Pvt Ltd. Mumbai, India. All other reagents were of analytical grade and used as purchased.

\section{Animals}

Thirty male Wistar rats weighing between 150-200g were procured from College of Veterinary and Animal Sciences, Kerala Veterinary and Animal Sciences University, Mannuthy, Thrissur, Kerala, India. All the 
animals were housed in polypropylene cages. Animals were fed with a standard rat pellet diet and were given drinking water ad libitum. The animals were housed, cared and used experimentally in accordance with the 'Guidelines for the Care and Use of Experimental Animals' and were approved by the Institutional Animal Ethical Committee (COPSRIPMS/IAEC/PG/P'COLOGY/05/2015-16). The animals were acclimatized to the laboratory conditions for $7 \mathrm{~d}$ and were randomly segregated into following groups with each group having five animals.

\section{Sample collection}

Fresh samples of Ginger (Zingiber officinalae Roscoe-ZINGIBERACEAE) were purchased from local market Coimbatore, India. The authentication of plants was carried out in Tamilnadu Agricultural University, Coimbatore (Identification No: BSI/SRC/5/23/2021/Tech/107)

\section{Animals and treatment schedule}

The entire treatment protocol was for $21 \mathrm{~d}$. In this treatment schedule, rats were randomly divided into five groups, consists of 6 animals each and treatment schedule was summarized as follows:

Group I: Normal saline treatment (i. p.)

Group II: 3-NP (10 mg/kg, i. p.)

Group III: F1 (10 mg/kg, i. p.)+3-NP (10 mg/kg, i. p.)

Group IV: F3 (10 mg/kg, i. p.)+3-NP (10 mg/kg, i. p.)

Group V: Ethanolic extract of Zingiber officinalae (EEZO) $(10 \mathrm{mg} / \mathrm{kg}$, i. p.)+3-NP (10 mg/kg, i. p.) [9].

Formulation of ginger loaded chitosan nanoparticles by ionic gelation method

Ginger-loaded chitosan nanoparticles were prepared by ionotropic gelation technique. Chitosan nanoparticles were prepared and Tween $80(0.5 \% \mathrm{v} / \mathrm{v})$ was added to prevent agglomeration at ambient temperature while stirring. Required quantity of chitosan, as shown in table 1 , was taken and dissolved in $5 \mathrm{ml}$ of $1 \% \mathrm{v} / \mathrm{v}$ acetic acid solution under stirring at $1000 \mathrm{rpm}$ for $10 \mathrm{~min} .50 \mathrm{mg}$ of the drug was dissolved in $85 \mathrm{ml}$ of $0.5 \% \mathrm{v} / \mathrm{v}$ Tween 80 solution $(0.5 \mathrm{ml}$ Tween $80 \mathrm{in} 100 \mathrm{ml}$ of double-distilled water) and this drug solution was then added to chitosan solution and stirred for $20 \mathrm{~min}$ at 1000 rpm using magnetic stirrer and $\mathrm{pH}$ of chitosan solution was adjusted to 4.6-4.8 with $1 \mathrm{~N} \mathrm{NaOH}$. Sodium tripolyphosphate solution was prepared by dissolving $20 \mathrm{mg}$ of sodium tripolyphosphate in $10 \mathrm{ml}$ of $0.5 \%$ Tween was added dropwise using a syringe under stirring. The suspension was then sonicated for $30 \mathrm{~min}$ and centrifuged at $5000 \mathrm{rpm}$ for another $30 \mathrm{~min}$ and was lyophilized at $\left(-40^{\circ} \mathrm{C}\right)$ for two days [10].

\section{Characterization of ginger loaded chitosan nanoparticles}

\section{Fourier transform infrared (FTIR) spectroscopy}

The FTIR spectra were recorded for ginger-loaded chitosan nanoparticles as well as for the physical mixture of drug and excipients using JASCO FTIR 4100 instrument in the frequency range of 400-4000 cm-1 with the resolution of $4 \mathrm{~cm}-1$ [11].

\section{Percentage yield}

Ginger-loaded chitosan nanoparticles were weighed after drying. The percentage yield was calculated using the formula given below [12]

$$
\% \text { Yield }=\frac{\text { Practical weight of nanoparticles obtained }}{\text { Theoretical weight of polymer and drug }} \times 100
$$

\section{Measurement of mean particle size}

The mean size of the nanoparticles and size distribution of ginger loaded chitosan nanoparticles was determined by Dynamic Light Scattering Technique method using Malvern Zeta sizer at $25^{\circ} \mathrm{C}$. The dried nanoparticles were dispersed in water to obtain proper light scattering intensity for prepared ginger nanoformulation [13].

\section{Determination of zeta potential}

Zeta potential is a measure of surface charge (electrophoretic mobility) and it is measured by Zeta sizer (Malvern Instrument) having Zeta cells, polycarbonate cells with gold plated electrodes using water as a medium for sample preparation [14].

\section{Determination of entrapment efficiency and drug loading}

The entrapment efficiency of ginger-loaded chitosan nanoparticles was determined by making a nanoparticle suspension using phosphate buffer of $\mathrm{pH} 6.8$ and sonicated in a bath sonicator and filtered. $1 \mathrm{ml}$ of the filtrate was further diluted to $10 \mathrm{ml}$ with phosphate buffer of $\mathrm{pH}$ 6.8 and the amount of drug was analysed spectrophotometrically at $280 \mathrm{~nm}$ (UV-Visible spectrophotometer, JASCO V-530). The amount of entrapped drugs was calculated from the equation $[15,16]$.

$$
\begin{gathered}
\text { Entrapment efficiency }(\%)= \\
\frac{\text { Total amount of drug added-Amount of free drug }}{\text { Amount of total drug }} \times 100
\end{gathered}
$$

$$
\text { Drug Loading }(\%)=\frac{\text { Total amount of drug added-Amount of free drug }}{\text { Amount of dry nanoparticles }} \times 100
$$

\section{In vitro drug release studies}

In vitro release of ginger-loaded chitosan nanoparticles was conducted by dialysis bag (Sigma, $1200 \mathrm{MW}$ cut off) with $200 \mathrm{ml}$ of phosphate buffer pH 6.8 at $37^{\circ} \mathrm{C} \pm 1{ }^{\circ} \mathrm{C}$. Nanoparticles equivalent to $20 \mathrm{mg}$ of ginger was dissolved in $2 \mathrm{ml}$ of phosphate buffer solution and placed in a dialysis bag (approximately $1.61 \mathrm{ml} / \mathrm{cm}$ ) which was kept in a $500 \mathrm{ml}$ beaker containing $150 \mathrm{ml}$ of buffer solution, which was kept on a magnetic stirrer maintained at $300 \mathrm{rpm}$ and at a temperature of $37 \pm 1^{\circ} \mathrm{C}$. Aliquots samples of $5 \mathrm{ml}$ were withdrawn at regular intervals and replaced with $5 \mathrm{ml}$ of fresh buffer to maintain a sink condition. The amount of drug released was measured by using a UV-Visible spectrophotometer at the wavelength of $280 \mathrm{~nm}$ against phosphate buffer $\mathrm{pH} 6.8$ as a blank [17].

\section{In vivo evaluation}

\section{Behavioural tests}

For the evaluation of behavioural performances of the animals, all the groups (I, II, III, IV and V) were assessed in the order of neurological scoring, elevated plus maze test, and hanging wire test. All the tests were performed between 9:00 AM to 5:00 PM. During analysis, the investigator was blind to the treatment groups.

\section{Neurological scoring}

Neurological scoring was assessed to measure the motor disturbance induced by 3-Nitro propionic acid (3-NP), based on their regular ambulatory movements. The scoring was done as per previous literature: normal, 0; general slowness of displacement due to mild hind limb impairment, 1; coordination loss and significant abnormality in gait, 2; hind limb paralysis, 3 ; inability to move due to impairment in both forelimbs and hind limbs, 4; recumbency, 5 [18].

\section{Hanging wire test}

In this test, the grip strength was measured indirectly by using a hanging wire test on the $7^{\text {th }}, 14^{\text {th }}, 21^{\text {st }}$ day of the treatment schedule. In this test, animals were allowed to hang their forelimbs on a steel wire with a diameter of $2 \mathrm{~mm}$ and a length of $80 \mathrm{~cm}$ elevated to a height of $50 \mathrm{~cm}$ from the ground, padded with a cushion to prevent injury to the animal. The latency to the grip loss was measured; the cut-off time was kept at $90 \mathrm{~s}$ [19].

\section{Elevated plus maze test}

The cognitive performance was measured by the elevated plus-maze test. The plus-maze has four arms $(50 \mathrm{~cm} \times 10 \mathrm{~cm})$ with two open arms and two closed arms, closed with a $40 \mathrm{~cm}$ height wall connected with a central platform of $10 \times 10 \mathrm{~cm}$ dimensions. Memory acquisition was measured on the $7^{\text {th }}, 14^{\text {th }}$ and $21^{\text {st }}$ day of the experiment by placing the animals individually on the open arm facing opposite to the central platform; the time taken by the animal to move from an open arm to the closed arm was measured as plusmaze latency (TL) [20].

Preparation of brain homogenate for biochemical and neurochemical estimations

On the $22^{\text {nd }}$ day, animals were euthanized under deep anaesthesia by using ketamine hydrochloride $(50 \mathrm{mg} / \mathrm{kg}$, i. p.) and xylazine $(10$ 
$\mathrm{mg} / \mathrm{kg}, \mathrm{i} . \mathrm{m}$.). The rats were transcardially perfused with ice-cold saline. The brain samples were removed by decapitation. Individual brain tissue samples (Cortex, Striatum and Hippocampus) were then homogenized with an ice-cold $0.1 \mathrm{M}$ phosphate buffer (7.4). The homogenate was centrifuged at $5000 \times \mathrm{g}$ for $15 \mathrm{~min}$ using a refrigerated centrifuge, and the aliquots of supernatant were separated and used for biochemical estimation.

\section{Measurement of oxidative stress parameters}

\section{Measurement of lipid peroxidation}

The quantitative measurement of malondialdehyde (end product of lipid peroxidation) in the brain striatum was performed according to the method of [21]. The amount of malondialdehyde (MDA) was measured after its reaction with thiobarbituric acid at $532 \mathrm{~nm}$ using a spectrophotometer (Shimadzu, UV-1700). The concentration of MDA was expressed as nmol per mg protein.

\section{Estimation of glutathione}

The level of reduced glutathione in the striatum of the brain was estimated according to the described method [22]. Absorbance was measured at $412 \mathrm{~nm}$ using a spectrophotometer (Shimadzu, UV1700). The concentration of glutathione was expressed as $\mu \mathrm{mol}$ per mg protein.

\section{Protein estimation}

The protein was measured by the Lowry method using Folin phenol reagent [23]. The phenolic group of tyrosine and trytophan residues (amino acid) in a protein will produce a blue-purple colour complex with Folin-Ciocalteu reagent, which consists of sodium tungstate molybdate and phosphate. Absorbance was measured at $660 \mathrm{~nm}$ using a spectrophotometer (Shimadzu, UV-1700).

\section{Estimation of superoxide dismutase}

The activity of SOD was determined using $100 \mu \mathrm{l}$ of $186 \mu \mathrm{l}$ phenazine methosulphate and $300 \mu \mathrm{l}$ of $17 \mathrm{mmol}$ sodium pyrophosphate buffer $(\mathrm{pH}$ 8.3). The tissue homogenate was initially centrifuged at $150 \mathrm{~g}$ for $10 \mathrm{~min}$ and then at 10,000 for $15 \mathrm{~min}$ to get the enzyme in the upper layer. The supernatant solution was gathered and $150 \mu \mathrm{l}$ of it was added to the aliquot containing $600 \mu \mathrm{l}$ of $0.052 \mathrm{mmol}$ of sodium pyrophosphate buffer $(\mathrm{pH} 7.0)$ and $50 \mu \mathrm{l}$ of $186 \mu \mathrm{M}$ of methosulphate. Lastly, $100 \mu \mathrm{l}$ of $780 \mu \mathrm{M}$ of NADH was added to initiate the enzymatic reaction. Glacial acetic acid $(500 \mu \mathrm{l})$ was added after $1 \mathrm{~min}$ to stop the reaction. The absorbance was measured at $560 \mathrm{~nm}$ to quantify the colour intensity. Results were expressed in units/mg protein [25].

\section{Estimation of catalase}

Catalase activity was evaluated by the breakdown of hydrogen peroxide and was measured at $240 \mathrm{~nm}$. The assay mixture consisted of $3 \mathrm{ml}$ of $\mathrm{H}_{2} \mathrm{O}_{2}$ phosphate buffer and $0.05 \mathrm{ml}$ of supernatant of tissue homogenate $(10 \%)$ The change in absorbance was recorded at 240 $\mathrm{nm}$ with UV spectrophotometer and the results were expressed as micromole $\mathrm{H}_{2} \mathrm{O}_{2}$ decomposed/mg protein/min [26].

\section{Estimation of acetylcholine esterase (AChE)}

Acetylcholinesterase levels were measured by Ellman's method. About $0.4 \mathrm{ml}$ of brain homogenate was added to the cuvette containing $2.6 \mathrm{ml}$ of $0.1 \mathrm{M}$ phosphate buffer and $100 \mu \mathrm{l}$ (5,5'-dithiobis-(2-nitrobenzoic acid) or DTNB. The contents were mixed thoroughly and the absorbance was measured at $412 \mathrm{~nm}$ using a spectrophotometer. When the absorbance reaches to the stable value, the basal reading was recorded. Then $100 \mu \mathrm{l}$ of acetylthiocholine iodide was added and the absorbance was noted for $10 \mathrm{~min}$ at an interval of $2 \mathrm{~min}$. Absorbance change was determined.

Enzymatic activity was calculated using the formula: $\mathrm{R}=5.74(10-4)$ $\Delta \mathrm{A} / \mathrm{Co}$

$\mathrm{R}=$ Rate in moles substrate hydrolysed $/ \mathrm{min} / \mathrm{g}$ of tissue $\Delta \mathrm{A} €$ hange in absorbance $/ \mathrm{min} \mathrm{Co}=$ Original concentration of tissue $(\mathrm{mg} / \mathrm{ml})$ [27].

\section{Statistical analysis}

Each group of rats $(n=6)$ was assigned to one specific drug treatment. All data are expressed as mean \pm SEM values. The data were analysed by using Kruskal Wallis one way analysis of variance (ANOVA). In all tests, $\mathrm{P}<0.001$ was considered as statistically significant.

\section{RESULTS AND DISCUSSION}

Table 1: Formula for ginger loaded chitosan nanoparticles

\begin{tabular}{llllll}
\hline Formulation & Chitosan (mg) & Ginger (mg) & $\mathbf{0 . 2 \%}$ Sodium tripolyphosphate (ml) & 1\% Acetic acid (ml) & 0.5\% Tween 80(ml) \\
\hline F1 & 50 & 20 & 10 & 5 & 5 \\
F2 & 100 & 20 & 10 & 5 & 85 \\
F3 & 150 & 10 & 10 & 5 & 55 \\
F4 & 200 & 20 & 10 & 5 & 85 \\
F5 & 250 & 20 & 85 & \\
\hline
\end{tabular}

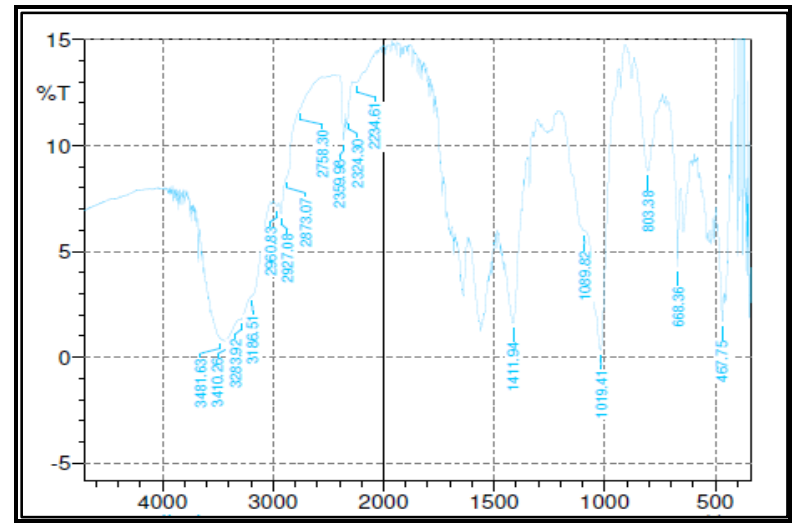

Fig. 1: FTIR spectra of physical admixture of ginger, chitosan and sodium tripolyphosphate

In this ionic gelation method of preparation of nanoparticles, chitosan in acetic acid solution acts as a source of the cation. When chitosan solution is added to polyanionic sodium tripolyphosphate solution, complexation occurs due to oppositely charged species, chitosan undergoes ionic gelation and precipitate to form spherical particles. Tween 80 is a surfactant adsorbed onto the surface of nanoparticles that prevents aggregation, reduces surface tension and thereby decreases the particle size. 


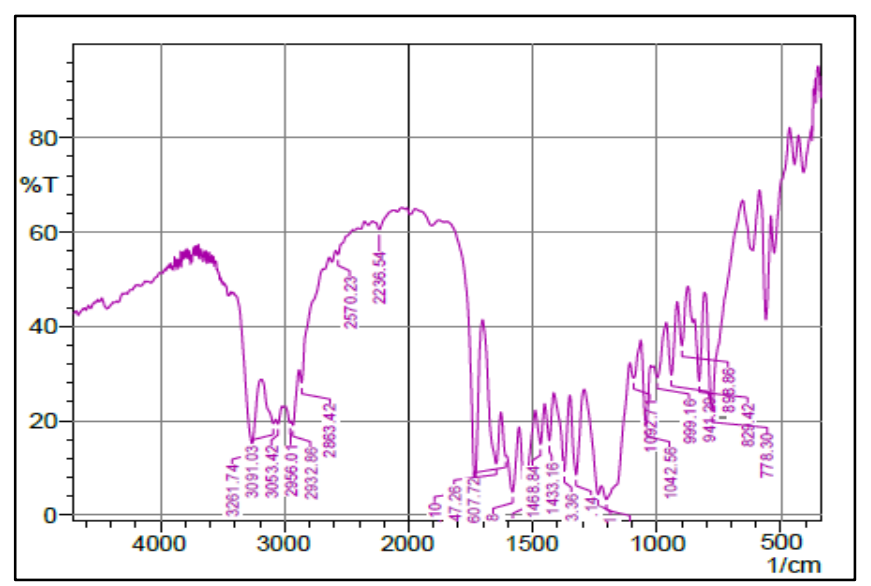

Fig. 2: FTIR spectra of ginger loaded chitosan nanoparticles

\section{Characterization of ginger loaded chitosan nanoparticles}

\section{Fourier transform infrared (FTIR) spectroscopy}

FTIR spectra of ginger loaded chitosan nanoparticles and the physical mixture of drug and excipients are given in fig. 1 and fig. 2, respectively

The peaks obtained in the FTIR spectrum of ginger nanoparticles are similar to that of peaks obtained in the FTIR spectrum of a physical mixture of ginger and excipients such as chitosan and sodium tripolyphosphate. It is therefore evident that ginger is compatible with its excipients.

\section{Percentage yield}

The percentage yield of ginger-loaded nanoparticles is depicted in fig. 3 and ranges from $80 \%$ to $95 \%$ for different formulations. It is therefore inferred that as the concentration of the polymer was increased, the percentage yield was also increased.

\section{Scanning electron microscopy (SEM)}

SEM images of best formulation F1 are shown in fig. 4-7. From SEM analysis, it is found that ginger-loaded chitosan nanoparticles are uniform, spherical and segregated.

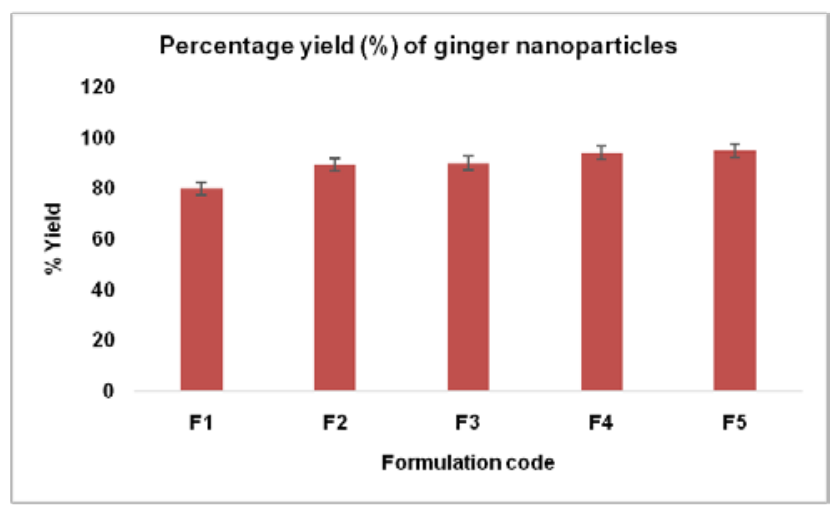

Fig. 3: Percentage yield of ginger loaded chitosan nanoparticles. Datas are represented as mean $\pm S D(n=3)$
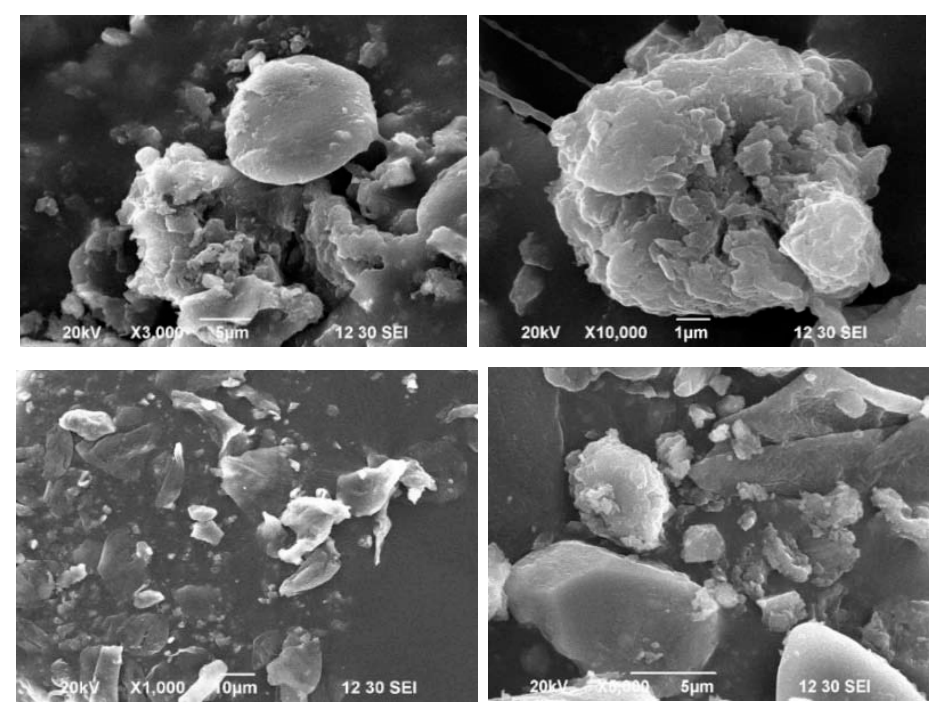

Fig. (4-7): SEM images of ginger loaded chitosan nanoparticles (F1) 


\section{Measurement of mean particle size}

The zeta size distribution of ginger-loaded chitosan nanoparticles is depicted in fig. 8. Particle size analysis showed that an average particle size of ginger-loaded chitosan nanoparticles (F1) was found to be $84.71 \mathrm{~nm}$ with a polydispersity index (PDI) value of 0.444 and with an intercept of 0.855 .

\section{Determination of zeta potential}

For ginger-loaded chitosan nanoparticles, the zeta potential was found to be- $35.7 \mathrm{mV}$ and it is depicted in fig. 9. Zeta potential analysis is carried out to find the surface charge of the particles to know it's stability during storage. Nanoparticles with a zeta potential value greater than $+25 \mathrm{mV}$ or less than $-25 \mathrm{mV}$ have higher degrees of stability. So zeta potential of ginger-loaded chitosan nanoparticles indicates that the herbal nanoformulation is stable.

\section{Determination of entrapment efficiency and drug loading}

As the concentration of polymer was increased, the entrapment efficiency and drug loading capacity were also increased (table 2).

\section{In vitro drug release studies}

From the in vitro release data it was found that formulations F1 and F3 showed the best release of $74.21 \%$ and $72.86 \%$ respectively at the end of $24 \mathrm{~h}$ among all the five formulations of ginger loaded chitosan nanoparticles. F2 Formulation shows $70.73 \%$ of drug release at the end of 24 h. F4 and F5 show $64.83 \%$ and $64.75 \%$, respectively. The release rate was related to drug: polymer ratio. Increase of drug release was found as a function of the drug: polymer ratio. It was observed that the drug release decreased with an increase in the amount of polymer for each formulation. This may be because the release of drug from the polymer matrix takes place after complete swelling of the polymer and as the amount of polymer in the formulation was increased, the time required to swell was also increased (fig. 10).

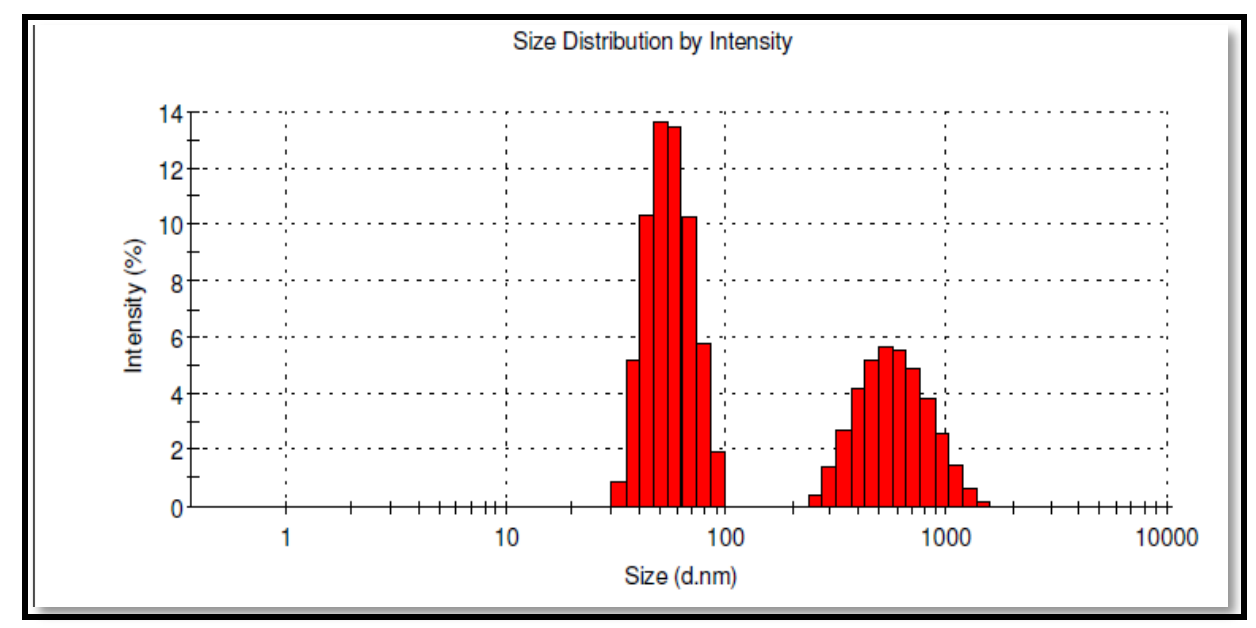

Fig. 8: Particle size distribution of ginger loaded chitosan nanoparticles (F1)

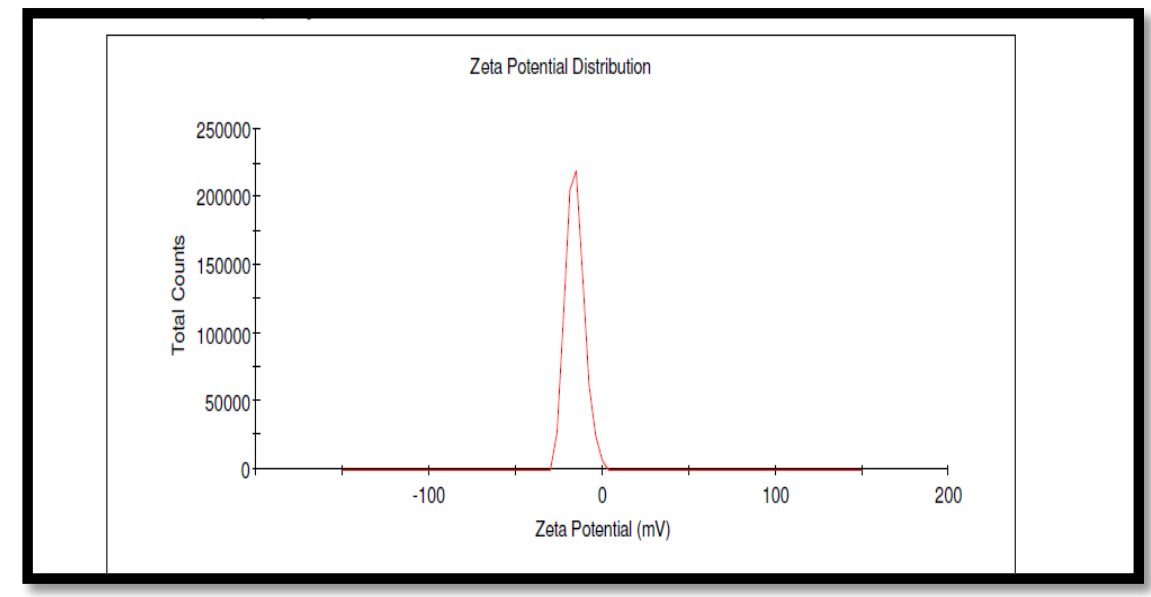

Fig. 9: Zeta potential of ginger loaded chitosan nanoparticles (F1)

Table 2: Determination of entrapment efficiency and drug loading

\begin{tabular}{llll}
\hline Formulation code & Polymer: drug & Entrapment efficiency \% & Drug loading \% \\
\hline F1 & $50: 50$ & $38 \pm 0.02$ & $10 \pm 0.05$ \\
F2 & $100: 50$ & $55 \pm 1.56$ & $13 \pm 0.88$ \\
F3 & $150: 50$ & $68 \pm 0.5$ & $15 \pm 0.37$ \\
F4 & $200: 50$ & $76 \pm 1.42$ & $16 \pm 0.21$ \\
F5 & $250: 50$ & $82 \pm 0.06$ & $18 \pm 0.48$ \\
\hline
\end{tabular}

$\mathrm{n}=3$, Values in mean $\pm \mathrm{SD}$ of three parallel measurements 


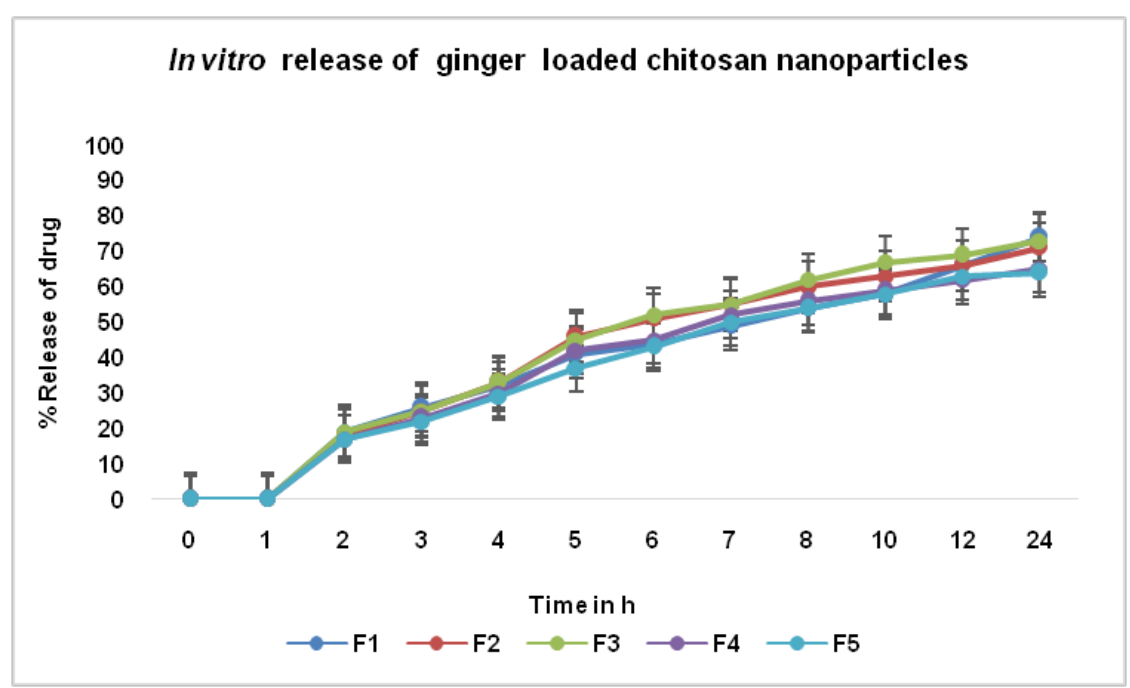

Fig. 10: In vitro release of ginger loaded chitosan nanoparticles, datas are represented as $m e a n \pm S D(n=3)$

\section{In vivo evaluation}

\section{Neurological scoring}

Administration of 3-NP resulted in abnormal motor behaviours like a marked gait abnormality, hind limb paralysis, and paralysis of both hind limbs and forelimbs $(\mathrm{P}<0.001)$. The administration of F1 and F3 has shown improvement in motor behavioural performances, but the improvement was not signficant when c ompared to 3-NP alone treatment group. All the data was tabulated in table 3.

\section{Hanging wire test}

Administration of 3-NP significantly $(\mathrm{P}<0.001)$ decreased the time to fall by hampering the grip strength when compared to the normal control group animals $[\mathrm{P}<0.0001]$. The $\mathrm{F} 1$ treatment groups and F3 treatment groups signficantly $(\mathrm{P}<0.01$ and $\mathrm{P}<0.05)$ increased the time to fall when compared to the 3-NP treatment and EEZO group of animals. This is shown in fig. 11.

\section{Elevated plus maze test}

Animals treated with 3-NP alone treatment group showed a significant $(\mathrm{P}<0.001)$ increase in transfer latency by hampering spatial memory when compared to the normal control group animals $[\mathrm{P}<0.0001]$. The F1 and F3 treatment groups ameliorated the spatial memory impairment sigrficantly $\quad(\mathrm{P}<0.01$ and $\mathrm{P}<0.001)$ by decreasing the transfer latency when compared to 3-NP alone treatment group and EEZO group of animals. This is shown in fig. 12.

Table 3: Effect of nanoformulation on neurological scoring in 3-NP neurotoxic rats

\begin{tabular}{lllll}
\hline $\begin{array}{l}\text { Treatment } \\
\text { group }\end{array}$ & $\begin{array}{l}\text { Normal } \\
\text { behaviour/Used } \\
\text { score=0 }\end{array}$ & $\begin{array}{l}\text { General } \\
\text { slowness/Used } \\
\text { score = 1 }\end{array}$ & $\begin{array}{l}\text { In-coordination and marked } \\
\text { gait abnormalities/Used } \\
\text { score = 2 }\end{array}$ & $\begin{array}{l}\text { Hind limb } \\
\text { paralysis/Used } \\
\text { score }=\mathbf{3}\end{array}$ \\
\hline Control & $6 / 6$ & $0 / 6$ & $0 / 6$ & $0 / 6$ \\
3-NP & $0 / 6$ & $1 / 6$ & $3 / 6$ & $2 / 6$ \\
F1+3-NP & $0 / 6$ & $3 / 6$ & $2 / 6$ & $0 / 6$ \\
F3+3-NP & $0 / 6$ & $3 / 6$ & $2 / 6$ & 0.0 \\
EEZO+3-NP & $0 / 6$ & $4 / 6$ & $2 / 6$ & $1.92 \pm 0.313$ \\
$\mathbf{4}$
\end{tabular}

Values are expressed as mean $\pm \operatorname{SEM}(n=6) ;{ }^{* * *}$ indicate $\mathrm{P}<0.001$ Vs control. Kruskal Wallis non-parametric analysis of variance

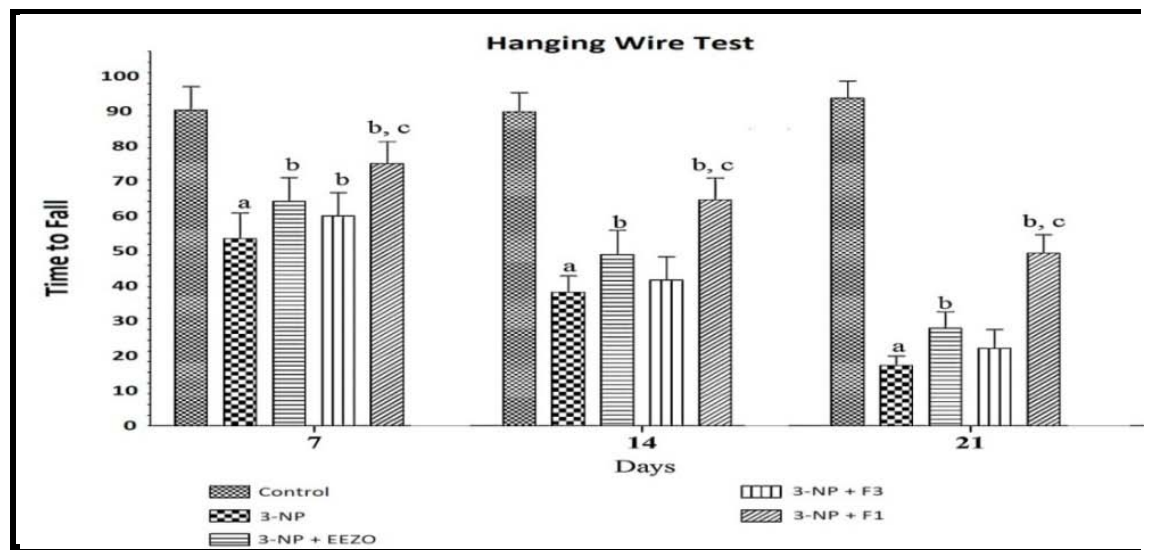

Fig. 11: Effect of Formulations on 3-NP induced changes in time to fall: data expressed as mean \pm SD: $p^{\mathrm{a}}<0.001 \mathrm{v} / \mathrm{s}$ Con, $\mathrm{p}^{\mathrm{b}}<0.05 \mathrm{v} / \mathrm{s} 3-\mathrm{NP}$, $\mathrm{p}^{\mathrm{c}}<0.05 \mathrm{v} / \mathrm{s}$ EEZO, $\mathrm{p}^{\mathrm{d}}<0.05 \mathrm{v} / \mathrm{s}$ F1 


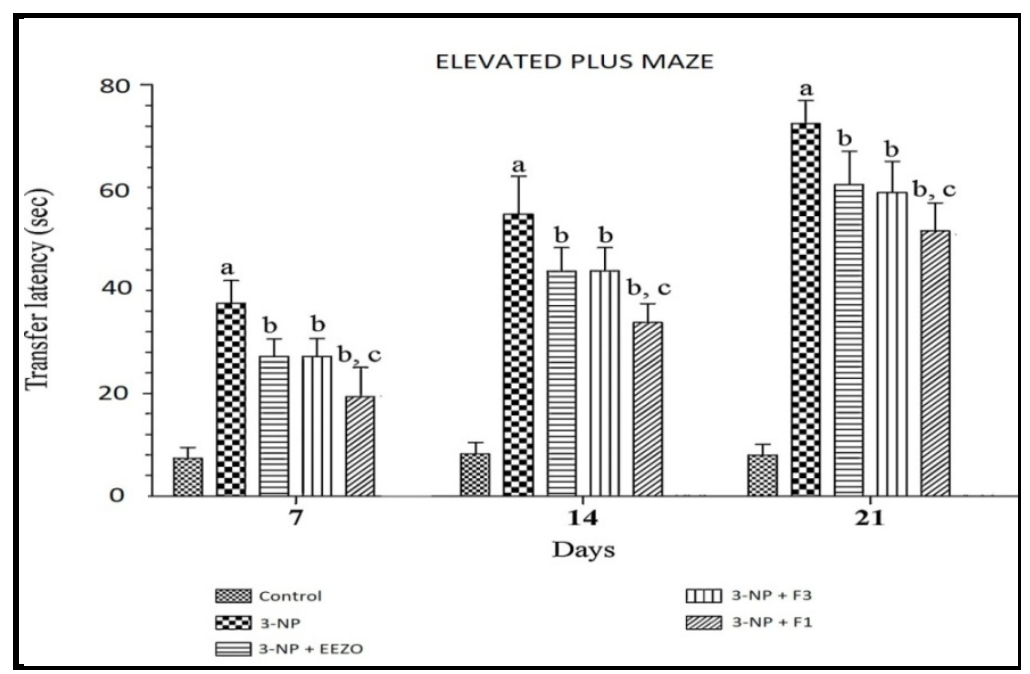

Fig. 12: Effect of formulations on 3-NP induced changes in transfer latency: data expressed as mean \pm SD: $\mathrm{p}^{\mathrm{a}}<0.001 \mathrm{v} / \mathrm{s}$ Con, $\mathrm{p}^{\mathrm{b}}<0.05 \mathrm{v} / \mathrm{s} 3-$ $\mathrm{NP}, \mathrm{p}^{\mathrm{c}}<0.05 \mathrm{v} / \mathrm{s}$ EEZO, $\mathrm{p}^{\mathrm{d}}<0.05 \mathrm{v} / \mathrm{s}$ F1

\section{Measurement of oxidative stress parameters}

Effect of formulations on lipid peroxidation and glutathione levels in 3-NP administered rats

Systemic administration of 3-NP (10 mg/kg/day; i. p.) significantly $(\mathrm{p}<0.001)$ increased lipid peroxidation and depleted glutathione enzyme activity in the striatum as compared to the normal control group (table 4). Pre-treatment with F1 and F3 attenuated lipid peroxidation and restored levels of antioxidant enzyme glutathione as compared to 3-NP alone treated group.

\section{Estimation of protein}

The total protein content of brain homogenate was significantly increased in the 3 -NP treated negative control group $(8.40 \pm 0.20$ $\mathrm{nmol} / \mathrm{mg}$ protein) as compared to the normal group (3.94 \pm 0.36 $\mathrm{nmol} / \mathrm{mg}$ protein). The rats treated with formulation F1 significantly decreased the protein content $(3.84 \pm 0.14 \mathrm{nmol} / \mathrm{mg}$ protein). The increased content of protein (carbonyl proteins) may be due to oxidative stress, which was decreased on the administration of ginger nanoparticles which might be due to the antioxidant effect of ginger. This is shown in table 4.

Table 4: Effect of formulations on lipid peroxidation, glutathione and protein levels in 3-NP administered rats

\begin{tabular}{llll}
\hline Treatment & MDA (n moles of MDA/mg protein) & GSH $(\boldsymbol{\mu}$ moles of GSH/mg protein) & Protein carbonyls (nmol/mg protein) \\
\hline Control & $0.216 \pm 0.136$ & $0.0324 \pm 0.0062$ & $3.94 \pm 0.36$ \\
3-NP & $1.748 \pm 0.108^{\mathrm{a}}$ & $0.0011 \pm 0.0008^{\mathrm{a}}$ & $8.40 \pm 0.20^{\mathrm{a}}$ \\
F1+3-NP & $0.402 \pm 0.122^{\mathrm{b} . \mathrm{d}}$ & $0.0273 \pm 0.0057^{\mathrm{b}, \mathrm{d}}$ & $2.39 \pm 0.14^{\mathrm{c}}$ \\
F3+3-NP & $0.781 \pm 0.184^{\mathrm{b}, \mathrm{c}}$ & $0.0180 \pm 0.0052^{\mathrm{b}, \mathrm{c}}$ & $2.84 \pm 0.45^{\mathrm{b}}$ \\
EEZO+3-NP & $1.021 \pm 0.220^{\mathrm{b}}$ & $0.0091 \pm 0.0020^{\mathrm{b}}$ & $3.19 \pm 0.24$ \\
\hline
\end{tabular}

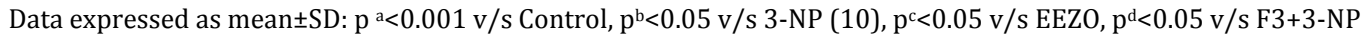

\section{Estimation of superoxide dismutase (SOD)}

The SOD level was significantly $(\mathrm{P}<0.01)$ reduced to $1.91 \pm 0.5$ units $/ \mathrm{mg}$ protein in 3-nitro propionic acid alone administered group compared to the control group (3.31 $\pm 0.09 \mu \mathrm{moles} / \mathrm{min} / \mathrm{mg}$ protein). Treatment with F1, EEZO $(10 \mathrm{mg} / \mathrm{kg})$ restored the activity of the SOD antioxidant enzyme to $3.14 \pm 1.28 \mu \mathrm{moles} / \mathrm{min} / \mathrm{mg}$ protein and $3.0 \pm 0.67$ $\mu \mathrm{moles} / \mathrm{min} / \mathrm{mg}$ protein, respectively and reduced generation of free radicals and neuronal damage. 3-nitro propionic acid-treated group (1.91 $\pm 0.5 \mu \mathrm{moles} / \mathrm{min} / \mathrm{mg}$ protein) and it was found to be significant with $\mathrm{P}<0.01$ ). Treatment with F3 shows the SOD antioxidant enzyme to $2.15 \pm 0.05 \mu \mathrm{moles} / \mathrm{min} / \mathrm{mg}$ protein. This suggests that the F1 has the capability to restore the level of SOD and reduce the formation of free radicals and associated oxidative stress (table 5).

\section{Estimation of catalase}

As catalase is an antioxidant enzyme which protects the brain from oxidative stress. The catalase level of brain homogenate was significantly $(\mathrm{p}<0.05)$ decreased in the negative control group $(1.91 \pm 0.50 \mu \mathrm{moles} / \mathrm{min} / \mathrm{mg}$ protein) as compared to the normal group $(4.22 \pm 0.51 \mu \mathrm{moles} / \mathrm{min} / \mathrm{mg}$ protein). The rats treated with F1 and F3 (10 mg/kg/p. o.) significantly elevated the catalase level values $(3.14 \pm 1.28$ and $2.89 \pm 1.04$ $\mu \mathrm{moles} / \mathrm{min} / \mathrm{mg}$ protein) when compared to the negative control. EEZO (10 mg/kg, p. o.) increased the catalase level $(3.12 \pm 0.39 \mu$ moles $/ \mathrm{min} / \mathrm{mg}$ protein). The catalase level was increased in the formulation $\mathrm{F} 1(10 \mathrm{mg} / \mathrm{kg})$ group when compared to all other groups (table 5).

Table 5: Biochemical estimation of enzymatic antioxidant in brain tissue homogenate

\begin{tabular}{lll}
\hline Groups & SOD & CAT \\
\hline Control. & $3.31 \pm 0.09$ & $4.22 \pm 0.51$ \\
Negative & $1.91 \pm 0.5^{*}$ & $1.91 \pm 0.50$ \\
F1 & $3.14 \pm 1.28^{*}$ & $3.20 \pm 0.72^{* *}$ \\
F3 & $2.15 \pm 0.05^{* *}$ & $2.89 \pm 1.04^{* *}$ \\
EEZO & $3.0 \pm 0.67^{* *}$ & $3.12 \pm 0.39^{* *}$ \\
\hline
\end{tabular}

Values are expressed as mean \pm SEM; $n=6$ in each group. SOD: units/mg tissue protein; CAT: $\mu$ moles/min/mg protein, $*$ denotes P<0.05, $* *$ denotes $\mathrm{P}<0.05$ when compared to negative control 


\section{Estimation of acetylcholine esterase (AChE) activity in the brain}

In cholinergic neurotransmission, AChE is the key enzyme involved and is a marker of extensive loss of cholinergic neurons in the brain. Acetylcholine was broken into acetate and choline in the presence of AChE and thereby it acts as a marker of extensive loss of cholinergic neurons in the brain. In the present study, a significant decrease in AChE level was observed in the 3-NP treated mice (Negative control). The percentage of the AChE inhibition in the brain homogenate was calculated for all the groups (fig. 13). The percentage of the AChE inhibition of the $\mathrm{F} 1(10 \mathrm{mg} / \mathrm{kg} / \mathrm{p}$. o.) was found to be $97.74 \%$ and the value compared with 3-nitro propionic acid $(20 \mathrm{mg} / \mathrm{kg} /$ i. p.) alone treated group was found to be only $29.16 \%$ on the $15^{\text {th }}$ day. The F3 and EEZO $(10 \mathrm{mg} / \mathrm{kg} / \mathrm{p}$. o.) treated rats resulted in the elevation of AChE inhibition $80.12 \%$ and $96.25 \%$, respectively. These results clearly demonstrated that nanoformulation F1 (10 mg/kg) effectively inhibited the AChE level and thereby it prevents the breakdown of acetylcholine and proves that ginger loaded chitosan nanoparticles improve memory, learning and neuroplasticity.

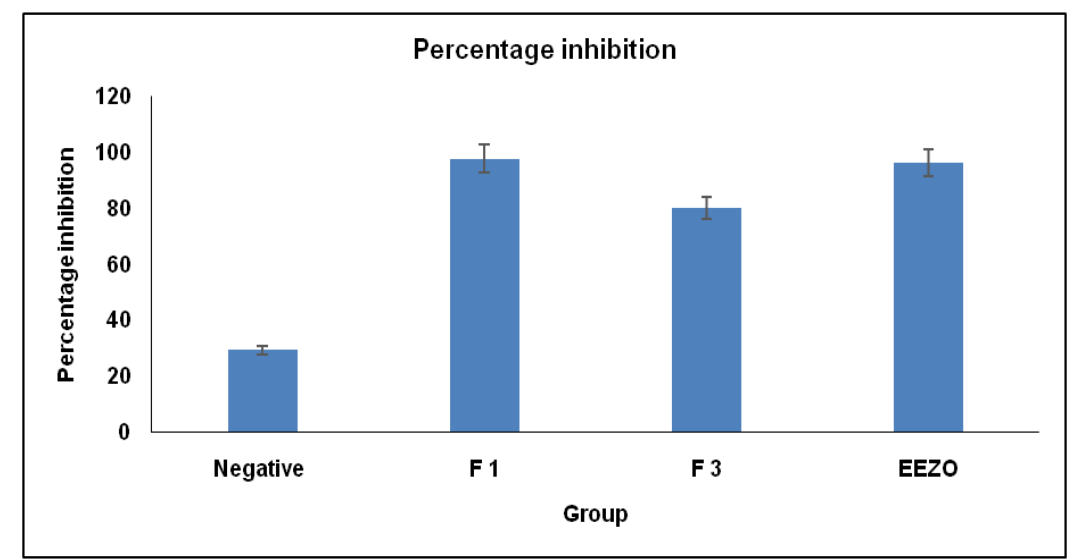

Fig. 13: Effect of EEZO, F1and F3 on brain AChE inhibitory activity in 3-Nitropropionic acid-induced HD rats. Datas are represented as mean \pm SD $(n=3)$

\section{CONCLUSION}

Huntington's disease is present at a global level, its prevalence in India is closer to that of the west than in other Asian countries. So, finding a cure is the necessity of the hour. Researchers have identified several avenues to further explore for treatment of Huntington's disease. One such step has been taken in the present research to combat HD. Despite Ginger being a brain tonic that has been reported in different neurodegenerative diseases, including HD, its low aqueous solubility and its ability to cross the blood-brain barrier limited its clinical applications. The present ginger loaded chitosan nanoformulations are more efficacious than their counterpart, the ethanolic extract of ginger. The neuroprotective effect of ginger nanoformulations was confirmed by the in vivo studies in 3-NP induced HD model Wistar rats. Whilst further research is needed to determine its toxicity and bioaccumulation in clinical settings. Eventually, the present ginger-loaded chitosan nanoformulation could be used as an optional and substantial approach to knock out HD.

\section{ACKNOWLEDGEMENT}

The authors sincerely thank Dr M. Gopal Rao, Professor and Head, Department of Pharmaceutics and Dr K Asok Kumar, Professor and Head, Department of Pharmacology College of Pharmacy, Sri Ramakrishna Hospital Campus, Coimbatore for providing the necessary facilities to carry out this work in their respective departments. Our special thanks to Dr Sam Johnson, Assistant Professor, Department of Pharmacology, Sri Ramakrishna Hospital Campus, Coimbatore for helping us in the interpretation of pharmacological data.

\section{FUNDING}

Nil

\section{AUTHORS CONTRIBUTIONS}

All authors have contributed equally.

\section{CONFLICTS OF INTERESTS}

The authors declare that there is no conflict of interest regarding the publication of this paper.

\section{REFERENCES}

1. Ohlmeier C, Saum KU, Galetzka W, Beier D, Gothe H. Epidemiology and health care utilization of patients suffering from Huntington's disease in germany: real-world evidence based on German claims data. BMC Neurol. 2019;19(1):318. doi: 10.1186/s12883-019-1556-3, PMID 31823737.

2. Bakr AF, Abdelgayed SS, EL-Tawil OS, Bakeer AM. Ginger extract and ginger nanoparticles; characterization and applications. Int J Vet Sci. 2020;9:203-9.

3. Manisha S, Nidhi S, Ramica S. Neuroprotective effect of Zingiber officinale in 3-NP-induced Huntington disease. IOSR J Pharm. 2012;2:61-70.

4. Miller PJ, Zaborszky L. 3-nitropropionic acid neurotoxicity: visualization by silver staining and implications for use as an animal model of Huntington's disease. Exp Neurol. 1997 Jul;146(1):212-29. doi: 10.1006/exnr.1997.6522, PMID 9225755.

5. Vis JC, Verbeek MM, De Waal RM, Ten Donkelaar HJ, Kremer HP. 3-nitropropionic acid induces a spectrum of Huntington's disease-like neuropathology in rat striatum. Neuropathol Appl Neurobiol. 1999 Dec;25(6):513-21. doi: 10.1046/j.13652990.1999.00212.x, PMID 10632901.

6. $\operatorname{Re} F$, Gregori M, Masserini M. Nanotechnology for neurodegenerative disorders. Nanomedicine. 2012 Sep;8Suppl 1:S51-8. doi: 10.1016/j.nano.2012.05.007, PMID 22640910.

7. Aderibigbe BA, Naki T. Chitosan-based nanocarriers for nose to brain delivery. Appl Sci. 2019;9(11):2219. doi: 10.3390/app9112219.

8. Del Prado Audelo ML, Caballero Floran IH, Meza Toledo JA, Mendoza Munoz N, Gonzalez Torres M, Floran B, Cortes H, Leyva Gomez G. Formulations of curcumin nanoparticles for brain diseases. Biomolecules. 2019 Feb 8;9(2):56. doi: 10.3390/biom9020056, PMID 30743984.

9. Sandhir R, Yadav A, Mehrotra A, Sunkaria A, Singh A, Sharma S. Curcumin nanoparticles attenuate neurochemical and neurobehavioral deficits in experimental model of Huntington's disease. NeuroMolecular Med. 2014 Mar;16(1):106-18. doi: 10.1007/s12017-013-8261-y, PMID 24008671.

10. Azalea DR, Mohambed M, Joji S, Sankar C, Mishra B. Design and evaluation of chitosan nanoparticles as novel drug carriers for 
the delivery of donepezil. Iran J Pharm Sci. 2012 Summer;8:155-64.

11. Akila RM, Saju SA. Design and characterization of biodegradable chitosan nanoparticles loaded with almotriptan malate for migraine therapy. Am J Pharm Health Res. 2018;6:1-15.

12. Khaira R, Sharma J, Saini V. Development and characterization of nanoparticles for the delivery of gemcitabine hydrochloride. Scientific World Journal. 2014. doi: 10.1155/2014/560962, PMID 24592173.

13. Patel PN, Patel LJ, Patel JK. Development and testing of novel tamoxifen citrate-loaded chitosan nanoparticles using ionic gelation method. Pharm Sin. 2011;2:17-25.

14. Selvaraj S, Niraimathi V, Nappinnai M. Formulation and evaluation of acyclovir loaded chitosan nanoparticles. Int J Pharm Sci Nanotechnol 2016;5:619-29.

15. Baby AAB, Sree N, Harsha K, Jayaveera N. Formulation and evaluation of levofloxacin nanoparticles by ionic gelation method. J Pharm Pharm Sci. 2012;1:7-15.

16. Nagarajan E, Shanmugasundaram P, Ravichandiran V, Vijayalakshmi A, Senthilnathan B, Masilamani K. Development and evaluation of chitosan-based polymeric nanoparticles of an antiulcer drug lansoprazole. J Appl Pharm Sci. 2015;5(4):20-5. doi: 10.7324/JAPS.2015.50404.

17. Remya PN, Damodharan N. Formulation, development and characterization of nimodipine loaded solid lipid nanoparticles. Int J Appl Pharm. 2020;12:265-71.

18. Patel BA, Arundell M, Parker KH, Yeoman MS, O’Hare D. Simple and rapid determination of serotonin and catecholamines in biological tissue using high-performance liquid chromatography with electrochemical detection. J Chromatogr B Anal Technol Biomed Life Sci. 2005;818(2):269-76. doi: 10.1016/j.jchromb.2005.01.008. PMID 15734169.
19. Ryan EP. Bioactive food components and health properties of rice bran. J Am Vet Med Assoc. 2011;238(5):593-600. doi 10.2460/javma.238.5.593, PMID 21355801.

20. Kumar P, Kalonia H, Kumar A. Possible GABAergic mechanism in the neuroprotective effect of gabapentin and lamotrigine against 3-nitropropionic acid induced neurotoxicity. Eur J Pharmacol. 2012;674(2-3):265-74. doi 10.1016/j.ejphar.2011.11.030, PMID 22154757.

21. Wills ED. Mechanisms of lipid peroxide formation in animal tissues. Biochem J. 1966;99(3):667-76. doi: 10.1042/bj0990667, PMID 5964963.

22. Ellman GL. Tissue sulfhydryl groups. Arch Biochem Biophys. 1959;82(1):70-7. doi: 10.1016/0003-9861(59)90090-6, PMID 13650640.

23. Lowry $\mathrm{OH}$, Rosebrough NJ, Farr AL, Randall RJ. Protein measurement with the Folin phenol reagent. J Biol Chem. 1951;193(1):265-75. doi: 10.1016/S0021-9258(19)52451-6, PMID 14907713.

24. King TE. Preparation of succinate dehydrogenase and reconstitution of succinate oxidase. Meth Enzymol. 1967;10:322-31. doi: 10.1016/0076-6879(67)10061-X.

25. Kono Y. Generation of superoxide radical during autoxidation of hydroxylamine and an assay for superoxide dismutase. Arch Biochem Biophys. 1978;186(1):189-95. doi: 10.1016/00039861(78)90479-4, PMID 24422.

26. Luck H. Catalase. In: Bergmeyer HU. editor. Methods of enzymatic analysis. New York: Academic Press; 1971. p. 88593.

27. Nathiya S, Nandhini A, Senthilkumar. Neuroprotective role of Salacia oblonga extracts against aluminium chloride-indicative stress in rat cortex. J Pharm Res. 2015;5:4344-7. 